\title{
LA PANTALLA FEMINISTA: FEMINIDAD SUFRAGISTA Y MASCULINIDAD HEGEMÓNICA. ANÁLISIS CINEMATOGRÁFICO: ÁNGELES DE HiERro (2004) Y LAS SUFRAGISTAS (2015)
}

\author{
Iván Gómez Beltrán \\ ivangom1@hotmail.com \\ Universidad de Oviedo - España
}

Recibido: 29-02-2016

Aceptado: 04-06-2016

\section{Resumen}

La cinematografía de los últimos años ha prestado especial atención a determinados procesos de la Historia del feminismo, uno de estos "hechos" lo constituye el sufragismo. A lo largo del texto se pretenderá ahondar en la politización de los mensajes fílmicos y por tanto en su comprensión/recepción como discurso político al alcance del público contemporáneo así como instrumentos productivos de una representación determinada de los géneros y sus alteridades. Todo ello sin olvidar los "efectos" -en tanto agentes culturales- que pueden producir en la sociedad. Para ello se utilizarán dos películas del cine mainstream contemporáneo Ángeles de Hierro (2004) y Las Sufragistas (2015) con la intención de analizar cómo la narración fílmica sirve a los intereses discursivos de la desmitificación de las mitologías antisufragistas así como al despliegue de la alteridad femenina sufragista y la comprobación de los posibles cambios y resistencias en el seno de la masculinidad.

Palabras Clave: Sufragismo, feminismo, género, alteridad, cine, feminidades, masculinidades.

\begin{abstract}
The cinematography of recent years has paid special attention to certain processes in the History of feminism; one of these "events" is the suffragist movement. Throughout the text, we will explore the politicization of filmic messages and their comprehension/reception as political discourse accessible to the contemporary audience as well as productive instruments of a particulargender representation and its othernesses. Not forgetting the "effects"as cultural agents- that can be translated into social changes. For this, two films of contemporary mainstream cinema, Iron Angels (2004) and Suffragette (2015), will be used with the intention to analyze how the filmic narrative discourse serves the interests of the demystification of the anti-suffragists mythologies, as well as the deployment of suffragist femininity otherness and the verification of possible changes and resistances within masculinity.
\end{abstract} Keywords: Suffrage movement, feminism, gender, otherness, cinema, femininities, masculinities. 


\section{Introducción: Activismo sufragista y representación cinematográfica}

"I won't give anything away until we have it all". Alice Paul; Ángeles con mandibula de hierro (2004) ${ }^{1}$

Uno de los momentos claves a nivel histórico-cultural en la etapa reciente de nuestra civilización es sin duda la adquisición del voto -quizá deba decirse arrebatamiento debido a las feroces resistencias patriarcales- por parte de las mujeres. Determinante, sin ninguna duda, porque marca el inicio del proceso de inserción de la mitad de la población en la abstracción política y jurídica que supone el concepto de ciudadanía, de la cual había permanecido excluida durante gran parte de la Historia. Aunque también por el enorme coste, tanto a nivel individual en cuanto mujeres y sufragistas, como a nivel colectivo, en la negación de una identidad anclada en la sororidad grupal. El sufragismo debe ser considerado como uno de los movimientos políticos más relevantes del siglo XX en Europa y EEUU, tanto por la importancia del hecho en sí mismo, como por la rica tradición cultural forjada con sangre y valentía y de la cual numerosos movimientos políticos son herederos.

El sufragismo puede ser entendido como una "radicalización”, (González Hernández, 2010: 57) de los ideales de la Francia revolucionaria de finales del XVIII momento en el que se configuraron los llamados iconos horizontales (Valcárcel, 1997: 163) es decir conceptualizaciones basadas en la abstracción del sujeto como por ejemplo la igualdad, la ciudadanía o la justicia una vez desarticulada la sociedad estamental. Con esto, el sufragismo no hizo sino más que llevar hasta sus últimas consecuencias políticas las promesas revolucionarias de igualdad de los individuos, que parecían haber sido interpretadas en un estricto masculino lingüístico que marginaba a las mujeres de la participación política y por lo tanto del espacio de significación e individuación. La concepción masculinista de la igualdad, que otorgaba una separación simbólico-espacial -no entendida como prohibición sino como complementariedad naturalizada de las esencias de género- va a ponerse en entredicho a través de la ocupación sistemática del ámbito público como acto político sustancial llevado a cabo por las sufragistas.

El voto se convertirá en el eje argumental fundamental de la articulación de la igualdad y por tanto el espacio público será visto como el punto clave de las operaciones sufragistas. Esto supone que se depositaron las esperanzas del cambio en el voto, no como único objetivo político (Valcárcel, 1994: 38) sino más bien como la sublimación de las esperanzas subversivas y reivindicativas feministas de las mujeres sufragistas. Como afirma María Jesús González (57: 2010): “[p]ara empezar querían el voto. Pero sólo para empezar”; su ambición política no se

\footnotetext{
"No regalaré nada hasta que lo tengamos todo" [Traducción propia]. A lo largo del texto se hará uso de la traducción directa del título original a pesar de que la versión en castellano sería: Ángeles de hierro.
} 
reducía a un mero cambio legal, por imprescindible que resultara sino que obedecía a un discurso ideológico más amplio que se desplegaba en su día a día, con todas las complejidades y también posibilidades que eso suponía.

Con esto, parece lógico que parte del cine feminista o al menos de intención reivindicativa haya prestado atención -por múltiples motivos e intereses- al movimiento por el voto de las mujeres; aunque su presencia cinematográfica sea insignificante en comparación a otros hechos históricos. Este énfasis no solo significa una mayor presencia pública del feminismo como teoría política sino que también supone la codificación de una serie de hitos en relación a la Historia feminista en el imaginario colectivo. No sin olvidar que dentro de esta representación se sanciona una normatividad por la cual una serie de recursos cinematográficos pasan a ser, sino esenciales, si determinantes para que el mensaje o mensajes fílmicos cumplan con los objetivos intencionales ideados por la dirección ${ }^{2}$. Podría decirse que el público, en tanto audiencia múltiple y receptiva (De Lauretis, 1987) reconstruye el mensaje fílmico como un proceso cognoscitivo por el cual asienta "lo conocido" sobre el feminismo, así como sobre "el modo o manera" en la que debe ser representado correctamente para potenciar las relaciones de identificación.

El cine, como una herramienta privilegiada debido a la conjunción de lo visual y lo sonoro, ofrece una variedad increíblemente rica de lenguajes que pueden ser descodificados para la mayor comprensión, no solo de la realidad sino también de la "virtualidad" discursiva y sus mecanismos de construcción de la verosimilitud. Esto quiere decir que puede funcionar por un lado como agente cultural en cuanto a que su visualización/identificación por parte del público afecta a su forma de concebir el mundo y por otro lado, como fuente documental que revela los dispositivos ideológicos o discursivos que sustentan las estructuras culturales y que se materializan a través de diferentes estrategias narrativas. En palabras del sociólogo Pierre Bourdieu (2007: 86) "estructuras estructuradas predispuestas a funcionar como estructuras estructurantes, es decir, como principios generadores y organizadores de prácticas y representaciones [...]”. En esta concepción el cine pasa de ser un mero depósito cultural a adquirir la capacidad de un instrumento político que condiciona su presente y que en definitiva tiene capacidad generativa.

Una de las complejidades que presenta el cine es que es presentado como un entretenimiento fútil en el que parece que no hay inscrita ninguna intención ideológica, esto es "al basarse en el potencial de registro de la fotografía unido a la proyección de una imagen aparentemente móvil, presenta toda la apariencia de ser un mensaje sin código una duplicación no mediatizada del mundo real" (Kuhn, 1991: 99). Es necesario introducirse en los mecanismos narrativos y de identificación así como analizar la recepción del texto fílmico por parte del

\footnotetext{
${ }^{2}$ Podría decirse que las alimentaciones forzosas son un hito narrativo -un momento clave que se convierte en una pieza imprescindible del puzle cinematográfico- que es representado en numerosos filmes de esta temática tanto por su potencia emotiva como dramática.
} 
público en función de diferentes variables viendo la virtualidad como creación y por tanto como posibilidad analítica pero siendo plenamente conscientes de que "el cine cuenta y, para contar mejor, para seducir a su público, inventa" (Sorling, 2005: 1). De acuerdo a esto la cinematografía puede servir como un elemento estabilizador o por el contrario subversivo de las dinámicas de sexo/género/sexualidad y de lo que se tratará precisamente es de analizar todas las posibilidades que un texto situado contextualmente ofrece, tratando de observar cuál es su intencionalidad o, en todo caso, cuál es la dinámica imperante.

En resumen, el cine debe ser comprendido como un instrumento político con una función cultural que puede diferir o no de la intencionalidad originaria. Se puede acceder a la representación de las alteridades de género en tanto discurso político a través de dichas producciones culturales desgranando los diferentes procesos formativos y sus interrelaciones para analizar la proyección que se hace del contexto y de la feminidad sufragista, en tanto alteridad o exterior constitutivo de la feminidad hegemónica (Butler, 2002). No debe olvidarse que el sufragismo se enfrentó de lleno contra la articulación dicotómica que producía la jerarquía y subordinación del género femenino y que por lo tanto removía las bases estructurales sobre las que la masculinidad hegemónica asentaba su opresión y moldeaba sus representaciones de subalternización (Nash, 2006).

Quizá uno de las películas más conocidas al respecto sea Ángeles con mandíbula de hierro (Iron Jewed Angels, 2004) que narra el costoso pero productivo esfuerzo de las mujeres sufragistas Norteamericanas del primer tercio del siglo XX, en especial de la protagonista Alice Paul (Hilary Swank) y del Partido Nacional de Mujeres (National Women's Party), fundado en 1916 por esta misma tras la expulsión de la Asociación Nacional del Sufragio de Mujeres Americanas (NAWSA; National American Woman Suffrage Association) de corte más moderado en sus prácticas activistas. El filme, dirigido por Katja von Garnier, constituye una de las obras más dinámicas, frescas y atractivas para el público en general, acercando la lucha sufragista en sus puntos más relevantes así como tratando de desarticular la "mitología antifeminista" inserta en el imaginario colectivo. Por otro lado Las sufragistas (2015) de Sarah Gavron narra de forma casi simétrica los sucesos acaecidos en Reino Unido durante aproximadamente el mismo periodo cronológico de la mano del personaje ficticio Maud Watts (Carey Mulligan) en la lucha de la Unión Social y Política de las Mujeres (WSPU; Women's Social and Political Union) fundado en 1903 por Emmeline Punkhurst quién introdujo un sufragismo más activo con el cambio de siglo (González Hernández, 2010: 62).

Ambas películas serán utilizadas en este texto como soporte fílmico básico. Ángeles de hierro supone uno de los mejores intentos de representar en pantalla la realidad sufragista sin perder la rapidez narrativa característica de lo mainstream. Por este hecho y debido a su contemporaneidad (2004) fusiona el dinamismo junto a una historia bien producida que fue muy bien acogida por el gran público, lo que la convierte en un ejemplo idóneo para este análisis. Por otro lado Las sufragistas destaca por su incuestionable novedad (2015); supone el 
más reciente acercamiento a la temática feminista/sufragista a través de la acumulación de los tópicos cinematográficos de este tipo de cine. Esto permitirá analizar cómo han evolucionado dichos "hitos narrativos" y a su vez, comprobar su efectividad así como nuevas preocupaciones que pudieran ser representadas de acuerdo a la actualidad político-social. De este modo, se seleccionan dos películas que conectan con las problemáticas representativas de sus precedentes así como con los conflictos actuales.

Los paralelismos entre ambas son inevitables, tanto por el contexto al que se refieren como por los recursos cinematográficos que son utilizados para mostrar la realidad social radicalmente misógina y opresiva en la que vivían las mujeres a través de su consideración como seres inferiores, imperfectos e improductivos fuera del ámbito de lo estrictamente doméstico. Con una diferencia de algo más de una década, ambas películas reflejan un mismo núcleo temático con un canon narrativo bastante común pero que, debido a su mayor dinamismo y compromiso histórico hace de Ángeles con mandíbula de hierro un filme más efectivo, si entendemos por eso, una mayor comprensión del mensaje narrativo y de sus implicaciones. Ambas películas hablan en términos feministas - no es casualidad que la dirección recaiga en manos de mujeres concienciadas- no solo del mismo movimiento político, sino que además lo hacen en términos muy similares, incluso en relación a otras obras como Las bostonianas (1984) o El caso Winslow (1999), lo que lleva directamente a valorar el establecimiento de un canon representativo del sufragismo.

Por un lado este canon supone la introducción del discurso feminista dentro de las formas narrativas mainstream, lo que da acceso a un mayor alcance de las teorizaciones feministas o al menos de la Historia del movimiento y sus obstáculos, pero por otro, no debe olvidarse que la cristalización de un canon supone por regla general la homogeneización de las prácticas, teorías y acciones llevadas a cabo en contextos diferentes y por tanto con particularidades históricoculturales que pueden diferir unas de otras en mayor o menor grado. Por ello la constatación de este canon debe hace oscilar el análisis entre la visibilización de la contingencia o no del uso de dichos recursos cinematográficos, de tal manera que se comprendan los procesos de su formación pero también la búsqueda de las conexiones que se establecen entre los hechos repetidos o "hitos narrativos" y la recepción del público y cuáles son las interrelaciones discursivas que se ponen en juego.

El objetivo fundamental del texto será, en definitiva, doble. Por un lado orientando al análisis hacia la alteridad sufragista se pretende profundizar en la representación del discurso de la radicalidad feminista así como a la construcción/deconstrucción y legitimación discursiva en relación a la contraposición categórica del sufragismo como activismo político con temáticas como: la feminidad hegemónica, la maternidad y consideración exclusivista del feminismo blanco de clase media. El otro objetivo gira en torno al análisis de la masculinidad hegemónica tratando de mostrar de qué manera se producen resistencias a los avances feministas pero también cuáles son los principales cambios -si los hay y de qué modo- de dicha identidad. 


\section{La sufragista como alteridad femenina}

Una de las acusaciones constantes a las que tuvo que enfrentarse la militancia sufragista, tanto británica como norteamericana fue la de "radicalismo", entendido este como una suerte de extremismo en el cual se sobrepasan los límites éticos admitidos y por lo tanto se antepone el objetivo en cuestión por encima de la estabilidad social o de los "valores sagrados y universales" que la constituyen. Las actividades eran consideradas propias de "hooligans", tal y como se afirma en Ángeles con mandibulas de hierro, tanto por gran parte de la población de carácter antisufragista, como por los sectores más moderados de la práctica política feminista. La ocupación directa de espacios públicos con manifestaciones, mítines, o acciones más violentas fundamentalmente a partir de 1912, el suicidio de Emily Wilding Davison o el destrozo realizado por Mary Richardson del cuadro de Velázquez "la Venus del espejo", así como las huelgas de hambre o actos de desobediencia civil, eran considerados actos vandálicos más que una metodología basada en el espectáculo público, la publicidad y el consumo del sufragismo (González Hernández, 2010).

Ambos filmes son un compendio de desmitificaciones de discursos antisufragistas pero también lo son de las consecuencias sociales a las que se enfrentaban debido a su empeño y tenacidad en la causa del voto y del feminismo en general. Tanto Alice Paul como Maud Watts serán las encargadas de dirigir al espectador a través de una diégesis repleta de inconvenientes en el objetivo principal. Si bien es cierto Ángeles con mandíbula de hierro diversifica en varios personajes problemáticas a las que muchas mujeres se enfrentan en lugar de concentrarlo en un único sujeto como Las sufragistas, esto la dota de mayor dinamismo y credibilidad mostrando el feminismo como un movimiento transnacional lleno de diversidad y a su vez multiplica las relaciones empático-afectivas que se establecen entre el espectador/a y el personaje, dando lugar a mayor número de posibilidades de identificación y por tanto a la sensación de vivencia de esa película. En este sentido, podría decirse que lo fundamental sería que el público recorriese la obra experimentando los sinsabores y las alegrías de sus protagonistas, lo que se busca es su proyección en el "interior", que traspase la pantalla con sus propias emociones rompiendo su bidimensionalidad.

Especial atención merece el concepto de identificación que aunque parezca de una corriente obviedad encierra un mecanismo imprescindible para la comprensión del desarrollo de este texto. La profesora de Geografía Social de la Universidad de Edimburgo Liz Bondi ha definido la identificación como: "a process through which the psychoanalytic subject absorbs and incorporates aspects or attributes of others, metabolising this material to generate his or her own identity" (Bondi, 2003: 68) . $^{3}$ Por lo que, haciendo ahora referencia al cine, hablamos de cómo el texto fílmico interpela al espectador/a para descodificar el lenguaje cinematográfico de

\footnotetext{
3“"Un proceso a través del cual el sujeto psicoanalítico absorbe e incorpora aspectos y atributos de otros, metabolizando este material para generar su propia identidad". [Traducción propia]
} 
acuerdo a actos conscientes o inconscientes que atañen a la constitución psicoanalítica del sujeto. La cuestión parte por tanto de la diferencia realizada por Annette Kuhn entre spectator y audience $\mathrm{i}$, o lo que es lo mismo entre el sujeto "situado dentro del proceso de significación cinematográfica" (Kuhn, 1991: 204) y la audiencia como conjunto social cosificado y universalizado. El spectator es la unidad individual que debe desentrañar el texto fílmico y que para ello pondrá en juego toda una serie de condicionamientos que determinarán su propia comprensión y que a su vez transformarán las mismas estructuras de las que se partía.

Partiendo de esta apreciación existe una diferencia fundamental entre ambas películas que condiciona enormemente la comprensión de los argumentos independientemente de que tanto el eje argumental como sus desarrollos sean muy similares. El punto de partida sobre el que parten no es el mismo. El film del año 2004, posiciona a Alice Paul como la principal protagonista de tal manera que el espectador/a debe entender su postura progresivamente -vista como radical desde el inicio-, mientras que en el caso del filme de Sarah Gavron, Maud Watts no es sufragista desde un primer momento, por el contrario la narración nos acerca su "conversión", sus dudas, sus miedos y por tanto la vulnerabilidad de un personaje que acaba siendo increíblemente resistente y adaptativo a las adversidades. El público menos docto en la Historia feminista probablemente simpatice en mayor medida o al menos más rápidamente con este personaje ya que no presenta demasiadas aristas, a diferencia de las comprometidas Alice Paul y Lucy Burns (Frances O'Connor) que desde su abultada experiencia aparecen representadas como más rígidas e incluso reacias a determinados comportamientos conservadores. Es debido a esto que el discurso, articulado desde dos puntos de origen bien distintos a pesar de las similitudes, obtiene efectos también diferentes en función del conocimiento previo del público. Las películas "enseñan" de manera similar qué fue el sufragismo, sin embargo es la perspectiva lo que se orienta de forma un tanto diferente.

El radicalismo político, no supondría un problema en términos generales, ya que va acompañado de diversos recursos narrativos que permiten una panorámica contextual que relativiza las acciones concretas. Fundamentalmente podemos hablar de dos: la feminidad sufragista como valiente, tenaz y en definitiva poseedora de la razón y verdad a juicio del ojo contemporáneo y junto a esto la resistencia constante de la masculinidad hegemónica materializada en el Estado o en personajes concretos, vista actualmente como arcaísmo discursivo y fundamentalmente vacío de razonamiento lógico.

La feminidad sufragista, o al menos el arquetipo representacional de las sufragistas - no del antisufragismo- suponía el cuestionamiento si no la deconstrucción del ideal hegemónico de feminidad, es decir, el prototipo sancionado de la buena mujer patriarcal en un contexto el victoriano y de doble moral sexual (Duby y Perrot, 2003: 49), en el que la dicotomización de los espacios heterosexualizados de género se intensificó: "[1]a lógica del discurso de género ha acabado definiendo un orden social de superioridad masculina, es decir, un sistema de género que la nueva sociedad contemporánea legitimaba al mismo tiempo que éste la legitimaba" (Nash, 2006: 43). 
Junto a esta deconstrucción de la propia categoría de la feminidad hegemónica, Ángeles con mandibulas de hierro apuesta por mostrar de forma directa las grietas que en parte, seccionaban el interior de la categoría poniendo en cuestión su uniformidad y en cierta manera su estabilidad. Son tres los conflictos que se representan: el generacional, el de clase y el de raza, presentes a lo largo de la consolidación del movimiento feminista. En primer lugar el problema generacional, inevitable no solo en el feminismo sino en cualquier movimiento sociopolítico en el que se encuentran resistencias a los cambios por cierto temor al retroceso. El enfrentamiento entre la NAWSA y el National Women's Party de Alice Paul ocupa un lugar determinante en la narración llegando a un punto de reconocimiento común que cierra las heridas abiertas a lo largo del filme a modo de cierre diegético y ensalza la sororidad identitaria por encima de las diferencias.

Por otro lado el problema de clase, bien representado en ambos filmes, en el que puede verse cierta tensión entre mujeres obreras que desconfían de las actitudes sufragistas así como muestran temor a perder su trabajo. Esto muestra, no solo el rechazo social del feminismo debido a los esfuerzos propagandistas antisufragistas, sino que a su vez pone sobre la mesa la difícil relación entre el feminismo y el socialismo, que parecían diferir de forma determinante en los objetivos que planteaban - proteccionismo- y en los métodos para llevarlos a cabo radicalismo o conservadurismo- (Anderson y Zinsser, 1991: 418). Derivado de la diferente perspectiva tomada en la narración ya comentada anteriormente, puede señalarse la aproximación tomada con respecto a la clase: mientras que en Las sufragistas se asiste a un proceso por el cual el espectador/a comprenderá las razones que llevan a militar en las filas sufragistas a Maud Watts, de clase humilde, trabajadora de una lavandería, Alice Paul es la encargada de adoctrinar políticamente a las mujeres obreras y de clase alta.

Otra de las problemáticas representadas con acierto es la de la raza, aunque es únicamente Ángeles con mandíbula de hierro la que menciona sin detenerse demasiado en dicho conflicto. La coexistencia de las reivindicaciones de las mujeres negras en los EEUU con el feminismo es indiscutible, al igual que lo son las disputas internas, incluso desde ópticas racistas. Como bien se sintetiza en la película el feminismo se enfrentaba a un panorama complejo en el que se debatía la aceptación social o la reivindicación: un feminismo para mujeres o para mujeres blancas tal y como una sufragista negra le pregunta a la protagonista.

La elevación de la Ciencia como la religión del siglo XX y por tanto el despliegue del discurso médico como el único verdadero y objetivo (Nash, 2006: 41) lleva a que las argumentaciones misóginas sean articuladas, ya no desde la complementariedad cristiana -que siguió siendo utilizada- sino más bien hacia las diferenciaciones de corte biologicista y por tanto a través de tautologías infranqueables que blindaban el género al sexo biológico y por lo tanto una serie de características, comportamientos y actitudes a un rasgo anatómico. De entre estas características hay tres que son representadas en estas películas y que deben ser mencionadas: la estética, el amor y la maternidad, siendo esta última la más importante para este análisis. Tres 
mitologías que cruzan transversalmente la vivencia femenina del género y que son brechas o zonas de sutura en las que el sufragismo pondrá su bandera.

En primer lugar quizá uno de los temas fundamentales de la feminidad es la maternidad. Es especialmente visible sobre todo en relación a Las sufragistas, en la que Maud Watts verá como su marido le termina impidiendo ver a su hijo debido a su militancia ${ }^{4}$, e incluso acaba por ceder en adopción a su hijo a otra familia ya que él se ve incapaz de darle la educación y el amor necesario en su crecimiento. "No puedo ser una madre para él" exclama en nombre de la sagrada ley edípica de la educación diferenciada y diferencial. La estricta compartimentación patriarcal aleja al padre de la educación de sus hijos y sobre todo de su cuidado, lo que se traduce en la incapacidad del hombre para hacer frente a una situación en la que no cuenta con la ayuda de su esposa. Maud ha perdido la razón, su histerismo natural se ha desatado a través de la militancia política junto a mujeres enloquecidas que solo saben chillar y reclamar un espacio que teórica y prácticamente no les pertenece. La lucha sufragista es vista como ilegítima y con ello su violencia es vista como desproporcionada y sobre todo como vandálica mientras que las ofensivas masculinistas, no es que cuenten con el apoyo del Estado, sino que es el mismo estado como ente patriarcal el que las articula.

La empatía es inevitable ante la fuerza simbólica de la escena y no por su carácter subversivo, sino más bien por su apelación a la propia maternidad como vínculo tan sagrado como irrompible. En pocos minutos el espectador/a sentirá lástima y rabia en proporciones similares porque se alude al vínculo social de la maternidad para potenciar emotivamente tanto el sufrimiento de las sufragistas como las consecuencias de su participación. Esta interpelación entenderse como una incoherencia producida por la contraposición del contexto histórico a representar y el lenguaje cinematográfico en sí mismo. Mientras que la realidad histórica de principios del siglo XX rechazaba cualquier categoría que pudiera poner en peligro la maternidad tradicional, anclada a un perfil de género hegemónico al servicio del varón y su prole, el lenguaje simbólico cinematográfico utiliza esta argumentación, anclada en el subconsciente cultural y colectivo como la primigenia. El discurso político de género idealizador de la maternidad, es utilizado en ambos casos apelando a las emociones pero con fines totalmente distintos, ya que mientras que en un caso se exige la exclusión de identidades alternas, en otro se busca la resignificación del discurso asentado.

Sufragismo y maternidad se oponen en la lógica patriarcal, porque cualquier desviación o transgresión de la dicotomización genérico-sexual supone la colonización de un espacio no solo prohibido sino contaminante, en la que lo abyecto es marginalizado y también configurado como infeccioso moralmente. La buena mujer, el ángel del hogar, esa conceptualización arquetípica que vivió su apogeo en la época de entreguerras, es el único idóneo para

\footnotetext{
${ }^{4}$ Puede hacerse una comparativa en Ángeles con mandibula de hierro, en la que Emily Leighton (Molly Parker) verá como su participación en la militancia, a pesar del cargo de responsabilidad pública de su marido, le llevará a que este le amenace con volver a verlos aseverando: "No sé qué juez en este distrito, acabaría dándote la custodia en este momento".
} 
desempeñar el cargo de educación de la prole, la sufragista, la nueva bruja del siglo XX, podía contaminar con sus ideas la frágil mente de la infancia.

Las sufragistas no solo pueden ser madres sino que además pueden enamorarse de hombres. La intensa propaganda antifeminista y antisufragista ha mostrado a estas mujeres como depredadoras de hombres, hechiceras y embaucadoras, como Circes, Medeas, Liliths, etc. Pseudomujeres que tratan de arrebatar a los hombres su puesto en la sociedad para establecer un hembrismo -entendido como oposición a lo machista o patriarcal- que relegaría a los hombres a un puesto subalterno en la sociedad. Una vez más la proyección de las ansiedades masculinistas lleva a la configuración del arquetipo de la sufragista como una mujer masculinizada, no sólo estéticamente sino en sus actitudes, lo que no hace sino más que reflejar la verdadera posición de los hombres en dicha sociedad. Incluso puede verse como Alice Paul se masturba durante una escena en la que se trata de insistir, tanto en alejar el prototipo de sufragista que no posee deseo sexual, como de remarcar su independencia y autonomía; la masturbación como epítome del empoderamiento político y sexual. El miedo masculino aparece cuando el privilegio parece tambalearse y por tanto cuando el podio está en entredicho. La táctica patriarcal más habitual será la de proyectar estas ansiedades para canalizarlas a través de un estereotipo de comportamiento que produzca la misma ansiedad en el resto de la sociedad. Tómense como ejemplo los comentarios con respecto a la sexualidad o a la supuesta "masculinización" que pueden verse a lo largo de ambos filmes, especialmente en el desfile de los Ángeles con mandíbulas de hierro. Es cierto que estas calificaciones surgen desde la valoración de la masculinidad como independencia en corporalizaciones de mujeres pero autoras como Judith Halberstam han señalado que la chicazo -o mujer joven masculina- solo es aceptada cuando no amenaza con prolongarse en el periodo adulto (Halberstam, 2008: 28) Junto a esto no debe olvidarse que el discurso que sustenta esta asociación con la independencia la sanciona como algo negativo e incluso peligroso y que por tanto legitima el uso de la violencia como restauradora del orden social. Pero por muchas fuerzas contrarias que tengan que enfrentar, las películas insisten en remarcar su capacidad adaptativa y resistente sin perder cierta vulnerabilidad que enfatiza su credibilidad.

Así mismo, no supone una novedad afirmar que las "historias de amor" suponen uno de los temas no solo más habituales sino también más rentables en las artes. Es casi impensable poder disfrutar de una obra artística del tipo que sea sin apreciar algún tipo de referencia al amor. En este caso Las sufragistas apuesta por una historia de amor diferente y es precisamente lo que en cierta medida la vacía de cierto carácter comercial en comparación con Ángeles con mandíbula de hierro. La narración a través de Maud es una historia de desamor, de desencanto con su vida pasada pero también de descubrimiento, de revelación de la realidad social, una especie de despertar de ese "mal que no tenía nombre" tal y como lo denominó Betty Friedan en su Mística de la feminidad (1963).

Junto a todo esto hay una característica que es quizá la más importante y con la que prácticamente todo el público estaría totalmente de acuerdo: la heroicidad y valentía de estas 
mujeres es innegable. Las sufragistas se enfrentan a múltiples resistencias, a cada cual más feroz, que afectan de lleno a su vida privada y por tanto a su negada individualidad, al igual que como pertenecientes a la categoría genérica colectiva de mujeres. Sus mandíbulas de hierro son el símbolo de la violación de los derechos de las mujeres y por tanto los derechos humanos. Las alimentaciones forzosas son una de las muchas torturas a las que fueron sometidas en su búsqueda incansable de la igualdad. Su radicalización, en tanto incremento de la violencia reactiva $^{5}$ de sus actividades es producto de la violencia legal, física y psicológica a la que fueron sometidas décadas antes de la "activación" del sufragismo, cuando no habían salido a las calles pero ya reclamaban su derecho a la ciudadanía (González Hernándes, 2010: 59-60). Ambos filmes muestran con suma claridad esta situación, visibilizando la realidad contextual en la que realizaron sus actividades y por tanto comprendiendo el conjunto de la panorámica y no los "hechos" concretos. Ninguna de esas mujeres hubiera querido pasar por una lucha tan encarnizada en la que tenían tanto que perder. Tal y como afirma Ben Weissman (Patrick Dempsey) en Ángeles con mandíbula de hierro, las sufragistas no habían hecho sino más que tomar al pie de la letra su afirmación: "Si quieres tinta, cómprate un bolígrafo". Aun así no debe caerse en el error de asumir cierto paralelismo entre la figura del héroe masculino y la de la sufragista ya que no cuentan con una tradición histórica ni representacional similar. Fundamentalmente porque la abstracción con la que se construye el arquetipo del héroe choca de lleno con la individualidad, personalización ${ }^{6}$ y concreción histórica con la que se moldean los personajes que encarnan las sufragistas.

En cualquier caso se huye fervientemente de la adquisición de la categoría de víctima. Entendida en el cine como un proceso narrativo -victimización- por la cual un personaje es modelado dentro de condiciones amenazantes para su bienestar físico o psicológico, lo que tiene consecuencias para el propio desarrollo diegético que suele centrarse en el establecimiento de relaciones de identificación-empatía con el espectador/a. De esta manera un personaje-víctima es configurado únicamente de acuerdo a su capacidad de resistencia defensiva y no se tienen en cuenta las relaciones de poder como relaciones independientes de dominación/sumisión. Las sufragistas son mujeres empoderadas porque comprenden la realidad marcada por la discriminación en la que viven y deciden lanzarse a cambiarla y por lo tanto porque deciden sobre sus propias vidas. Su sufrimiento no limita ni sus capacidades ni sus posibilidades y sobre todo no las caracteriza como lo hace su fuerza.

\footnotetext{
${ }^{5}$ Se utiliza el adjetivo de "reactiva" para resaltar que el aumento de las actividades violentas así como su intensificación obedecen no a un deseo fortuito sino a la necesidad de contrarrestar las oleadas machistas que asolaban sus actividades tanto a través del Estado como institución -tómese como ejemplo la Ley del Gato y el Ratón de 1912- como de la población civil desfavorable al voto de las mujeres.

${ }^{6}$ Con esto no se quiere decir que desde una perspectiva Histórica no sea fundamental la recuperación de todos y cada uno de los nombres y apellidos de las mujeres que se enfrentaron al statu quo por la obtención de sus derechos, sino más bien que el énfasis cinematográfico en la personalización no tiene por qué ir de la mano con el interés de visibilización histórica; son ámbitos y por lo tanto intereses que pueden diferir.
} 


\section{Las mandíbulas de hierro del patriarcado}

La intención de estas obras, tal y como se ha descrito brevemente, ha sido la de desmitificar, y por tanto romper con las numerosas tradiciones culturales que vinculaban dualismos excluyentes a la categoría de mujer entre ellos la maternidad, el amor, la estética o la valentía. Dicha revaloración se da en un complejo juego de relaciones en el seno de las dinámicas de género y por tanto estos posicionamientos discursivos deben tener un efecto reflejo en la identidad normativa por excelencia es decir la masculinidad hegemónica. Tal y como afirma la socióloga australiana Raewyn Connell (2015: 71): “no masculinity arises except in a system of gender relations"?

La masculinidad, comprendida entonces como una identidad histórica (Kimmel: 1987) y por tanto como una construcción que obedece a un espacio y tiempo $\operatorname{concretos}^{8} \mathrm{y}$ que se adscribe al varón a través de su asociación a un sexo verdadero inexcusable que sirve como ideal regulatorio (Butler, 2002: 18). A través de un circuito lógico cerrado en el que la argumentación biologicista elimina cualquier posibilidad de cuestionamiento de sí misma naturalizando el conjunto; dicho de otro modo: preguntarse sobre la identidad lleva a la valoración anatómica y viceversa. En palabras de la historiadora Mary Nash (2006: 42): “[1]a naturalización de la diferencia y el esencialismo biológico [...] [s]e han comportado como configuradores de prácticas sociales que niegan la categoría de sujetos históricos a algunos grupos identificados como "otros".

La masculinidad hegemónica ha sido conceptualizada por diversas autoras/es (Kimmel, 1987; Gilmore, 1990; Schippers, 2007; Connell, 2015) que han centrado su análisis en la opresión ejercida tanto a las mujeres como dentro del propio grupo, mediante la consideración transversal de otras categorías -sexualidad, raza, clase, diversidad funcional, etc.-. La relevancia de la identificación de la hegemonía gramsciana como factor fundamental radica en la transformación de los intereses masculinos en intereses colectivos, es decir, el conjunto de las operaciones por las que un grupo social concreto construye el deseo del conjunto total a partir del suyo propio naturalizando dicho mecanismo y por tanto invisibilizando dicha instrumentalización del poder. En este sentido se hace referencia a un proceso de universalización en la que el hombre se eleva como el total a través de la abyección de la mujer en ese proceso de encarnación de lo genéricamente humano: "alteridad, inmanencia e inesencialidad, versus mismidad, trascendencia y esencialidad como características que se reservarían para sí" (Amorós, 1998: 46). En este sentido, la masculinidad debe ser asociada a formas coercitivas del ejercicio del poder puesto que la única manera de sostener dicha posición

\footnotetext{
7“No surge ninguna masculinidad excepto en un sistema de relaciones de género". [Traducción propia.]

${ }^{8}$ Decir esto no es afirmar que sea una concreción histórica, sino que es precisamente su adaptación a diferentes periodos, movimientos y etapas socio-culturales lo que determina su resistencia.
} 
es a través de la subalternización de aquellas identidades que se configuran como las opuestas, concretamente la feminidad. Algunas de estas formas serían: el control, dominación, fuerza, protección, competición, victoria, violencia, agresividad, etc... Quizá sea necesario afirmar, que las mandíbulas de hierro parecían estar en otro bando y mordiendo con fuerza.

Ni duda cabe, que los ejemplos de estas actitudes en ambas películas son numerosos, desde la violencia legal directa a través de leyes creadas expresamente para contener el avance sufragista, pasando por la violencia ejercida por las difamaciones lanzadas por los medios de comunicación de masas, y por su puesto la llevada a cabo por las personas cercanas o familiares en el ámbito del hogar o del trabajo. Como se ha comentado la alimentación forzosa fue solo una de las múltiples formas de sojuzgación y por tanto de sometimiento implacable de un avance que era visto como una amenaza para la "autoidentidad" masculina. Es importante detenerse entonces en cómo estos filmes reflejan esas reacciones discursivas provocadas por la inestabilidad genérica causada por el flujo reivindicativo de las sufragistas y por tanto ver cuáles son las maneras en las que la argumentación se orienta -en el despliegue de un espacio de negociación/validación de las características identitarias culturalmente sancionadas, es decir negadas/admitidas- a la eliminación del movimiento político.

Una escena que refleja estas prácticas con claridad puede verse en Ángeles con mandíbulas de hierro, concretamente en el desfile realizado por las mujeres como parte de un nuevo activismo visible públicamente en el que participaban diversos grupos, los conservadores y los más radicales ${ }^{9}$, incluidas mujeres negras y obreras a modo de representación del feminismo como un movimiento transnacional y transversal interdependiente. Las imágenes recorren los rostros de las diferentes facciones - conocidas ya por el espectador/a- en un intento de unificación a través del objetivo principal del voto, pero progresivamente se intercalan tres conjuntos de imágenes que servirán para ejemplificar estas formas de opresión que dichos filmes representan con gran claridad: el Estado representado por el presidente, la violencia social y la violencia policial.

Tras unos segundos en los que se produce el desfile sin ningún incidente, se puede ver como progresivamente el ambiente de los hombres situados entre el público que asiste para contemplar el desfile comienza a caldearse hasta el punto de llegar a las amenazas físicas: "si tú fueras mi mujer, te golpearía la cabeza”. Estas amenazas no hacen sino más que anticipar lo que ocurrirá a continuación ante la permisividad de la policía, mostrada a través de rápidos primeros planos que indican la aprobación de dichos comentarios e incluso del uso de la violencia física. Justo inmediatamente después, la imagen se traslada a otro punto de la ciudad de Washington para reflejar la salida del Presidente de los EEUU de uno de los hoteles de la ciudad, en el que no parece haber nadie, ante lo cual su esposa comenta: "Pensé que habría una gran multitud.

\footnotetext{
${ }^{9}$ Cabe añadir que existía una diferencia nominal entre ambos grupos. Las más conservadoras se autodenominaban sufragistas mientras que el grupo radical adquirió la denominación de suffraguettes (González Hernández, 2010).
} 
¿Dónde está todo el mundo? ${ }^{10}$. Hasta el momento esta escena tiene dos claras intenciones políticas: por un lado mostrar el marcado antisufragismo del Estado como institución masculinista/heterosexista y por otro la negativa de la sociedad y en concreto de los varones a aceptar sin previo enfrentamiento las reclamaciones realizadas por las mujeres. Mientras que el Estado hace caso omiso de sus reivindicaciones, rechazando una y otra vez las enmiendas propuestas, la población centra sus esfuerzos en socavar cualquier aspiración posible de las sufragistas aseverando su intención de "ser hombres" y de ocupar un lugar que les está vetado. Si las mujeres habían decidido socavar los principios patriarcales quedaba en manos del Estado llevar a cabo toda una serie de dispositivos que en conjunto sirvieran para recomponer el puzle político del género y para ello se sirve de una violencia extrema, radical y directa, dirigida de lleno contra la integridad física y/o psicológica de las sufragistas y de cualquier persona que pudiera prestarles ayuda. La tranquilidad del viaje del Presidente de los EEUU contrasta con desolación de la enorme avenida de la ciudad de Washington plagada de banderas sufragistas, instrumentos musicales y flores, todo ello después de que se sucediera la restitución patriarcal de una masa masculina totalmente enfurecida.

Lo que se pone de manifiesto en estas imágenes y en otras muchas de ambas películas es el propio temor a la desestabilización de las dinámicas de género, o dicho de otro modo, la posibilidad de perder los privilegios auto-otorgados. Ambas directoras insisten en representar una masculinidad hegemónica muy rígida por no decir sólida ante los cambios sociales, haciendo especial hincapié en las posibilidades de coerción que tenían a su disposición, no solo por contar con la autoridad legal, sino porque esta va de la mano de la económica, la estatal y la cultural. El núcleo radica entonces, no solo en las prácticas de dominación/sumisión, sino también en contar con la validación social para llevarlas a cabo.

Dicha situación se pondrá en entredicho tras la $1^{\circ}$ Guerra Mundial, en la cual las mujeres ocuparon los sectores productivos abandonados por los militares que marcharon al frente de combate. El deseo de ambos bloques beligerantes de llevar a cabo una guerra rápida chocará con los acontecimientos, lo que obligará a una guerra "material” y "prolongada" que necesita de "el sostén de la retaguardia, el concurso de las mujeres (Duby y Perrot, 2003: 53). Durante los cuatro años del conflicto fueron las encargadas de mantener la producción y el suministro de los bienes necesarios para el avance del país, desmontando las argumentaciones que argüían su incapacidad para tal tarea (Anderson y Zinsser, 1991: 415). Ya desde los años anteriores a la guerra, concretamente entre 1912 y 1914 (González Hernández, 2010: 60) se intensificaron las acciones sufragistas por la necesidad de aumentar la presión política hacia el Estado que permanecía pasivo ante sus reivindicaciones. Tras la guerra, las mujeres sufragistas van a

\footnotetext{
${ }^{10}$ En adhesión a esto puede añadirse como el leitmotive musical de la película aparece en momentos en los que la represión se muestra más extrema. Tanto en las alimentaciones forzosas como en los ataques al desfile se podrá escuchar moldeando la escena para su mayor carga dramática, al igual que ocurre en el caso de Las Sufragistas con la muerte de Emily Wilding Davison.
} 
oscilar entre el nacionalismo favorable a la participación en el conflicto y por lo tanto a deponer la causa feminista, y entre el sufragismo activo que consideraba que su causa era tan importante como la guerra misma y que ya habían esperado demasiado tiempo. Lo que está claro es que, tanto en el contexto europeo como en el norteamericano, la guerra supondrá mayoritariamente el ascenso del nacionalismo y por tanto la excusa perfecta para apartar momentáneamente el tema del voto. Las mismas feministas, incluso las líderes históricas del movimiento Emmeline y Christabel Punkhurst se centraron en actividades de voluntariado y asistencia (Zinsser, 1991: 415; Duby y Perrot, 2003: 51).

Sería ingenuo pensar que dado el movimiento o fluidez de las dinámicas del sistema sexo/género no se habría dado ningún cambio en la concepción o los parámetros constitutivos de la masculinidad. No se está haciendo referencia en este caso a los grupos de hombres feministas que participaron o colaboraron con la causa sufragista -como el caso de la británica Unión Social y Política de los Hombres (González Hernández, 2010: 70)- sino a una relajación de las actitudes más retrógradas en el seno de la masculinidad como resultado del empuje feminista ya desde el siglo XVIII. Considerando esto, debe hablarse de un sexismo benévolo ${ }^{11}$ (Expósito, Moya y Glick, 1998: 161) basado en la edulcoración de las formas de sexismo más extremas (sexismo hostil) para ajustarse a las peticiones de las mujeres sin llevar a cabo una verdadera deconstrucción del núcleo de la identidad. Una suerte de paternalismo, en el que a través, bien de la idealización de la figura de la mujer como musa o como desvalida necesitada de protección, como "objeto" decorativo imprescindible, se reconocen ciertas cualidades femeninas positivas que buscan únicamente el reforzamiento de lo femenino en tanto subalternidad. Una feminidad idealizada construida con la intención de estancar el avance feminista a través de la reificación y endiosamiento estético que impediría la actuación política. Los dioses no participan en asuntos humanos, las diosas tampoco, eso queda en manos de los hombres.

Encontramos ejemplos de estas actitudes en ambas películas. En Las sufragistas, será Hugh Ellyn (Finbar Lynch), marido de la sufragista Edith Ellyn (Helena Bonham Carter) quien tras su apoyo constante en la película a la causa se antepondrá entre su esposa y la asistencia al Derby de Epsom porque su estado de salud era un tanto precario. De esta manera es el hombre el que decide "benévolamente" por el bien de su esposa, encerrándola en un trastero para que no pueda asistir, colocando sus intereses por encima de la voluntad y por lo tanto de la decisión de Edith. Podría argumentarse que dicha actuación está justificada ya que lo que está en juego es la vida de una persona, pero dicha afirmación no hace sino más que olvidar algo fundamental: la voluntad individual y por lo tanto el derecho a decidir, algo por lo que el feminismo y en este

\footnotetext{
${ }^{11}$ Según el/la autor/a Peter Glick y Susan T. Fiske el sexismo debe ser considerado como ambivalente y por lo tanto en sus manifestaciones podrían encontrarse formas hostiles y otras benévolas, en sus propias palabras: "We view sexism as a multidimensional construct that encompasses two sets of sexist attitudes: hostile and benevolent sexism" (Glick y Fiske, 1996: 491).
} 
caso el sufragismo han luchado y luchan aun hoy en día. La voluntad de Edith, en este caso, evitando generalizaciones, es irreductible.

Tómese como ejemplo, no ya otra escena sino un personaje en sí mismo en Ángeles con mandíbula de hierro en la que Alice Paul, conoce a Ben Weissman un dibujante del periódico Washington Post. Cuando se conocen tienen una conversación en la que la Alice rebate los argumentos antisufragistas que son lanzados con elegancia por su acompañante: desde una comparativa con la consecución del voto por los varones negros norteamericanos y su inutilidad para cambiar la realidad racista, hasta la afirmación de que una vez tuvieran el voto legalizarían las prácticas de control de la natalidad. A esto Alice contesta rotundamente:

"Ese no es el punto [...]. Somos ciudadanas legítimas. Pagamos impuestos sin tener acceso a la representación, no se nos permite ser jurados, por lo que no estamos siendo juzgadas por nuestras iguales. Es inconcebible, por no decir anticonstitucional. Nosotras no hacemos las leyes pero tenemos que obedecerlas como niñas $[\ldots]$ ”.

Pero lo llamativo en este momento no es la brillante argumentación, sino la actuación del hombre que la observa con un rostro complaciente, como si le agradara y le causara gracia ver a una mujer con capacidad intelectual para superarle. Esto queda más que claro en su siguiente intervención: “¿eras la chica más lista de tú clase?”, ante su incapacidad de rebatir, corta la argumentación con una valoración que en cierta manera ridiculiza a su oponente. Aun así, cabe mencionar que es consciente de que el interés -en un inicio- que muestra sufragista por él radica únicamente en su trabajo y en las posibilidades propagandísticas que se puedan derivar de su encuentro. En cualquier caso esto no niega el sexismo benévolo presente en la escena y en la masculinidad desplegada por el personaje, el interés como motor motivación de la actuación de Alice Paul no minimiza el comportamiento sexista del periodista.

Una masculinidad hegemónica que muestra no solo sus garras sino también sus mandíbulas en múltiples facetas del día a día y que ambas películas aciertan en reproducir a través de momentos icónicos como algunos mencionados: la maternidad como recurso sentimental, la alimentación forzosa como culmen del sufrimiento, los dilemas éticos ante la radicalización de la militancia y ante el nacionalismo desatado durante la primera guerra mundial. Todas estas cuestiones y otras, forman un entramado discursivo que acerca el feminismo a la población, hombres y mujeres, promoviendo el reconocimiento de figuras históricas imprescindibles para la valoración del presente y del pasado promoviendo el análisis crítico de las estructuras actuales de poder. Quizá sea excesivo pensar que un filme pueda llegar tan hondo y calar produciendo una reflexión tan importante, pero en cualquier caso la cinematografía sufragista no se centra únicamente en agradar, sino que su intencionalidad política de visibilización es su característica primordial. 


\section{Conclusiones}

El sufragismo, como movimiento político, configuró una identidad basada en la resistencia al orden patriarcal y en concreto a la masculinidad hegemónica. Se delimitaron formas de participación que progresivamente debido a la falta de atención por parte de la sociedad y el Estado dieron como resultado la intensificación y radicalización de sus actividades así como sus ideologías. Si la construcción de la identidad requiere tanto de una definición positiva de sus integrantes como de un conjunto de negatividades (Della Porta y Diani, 2006: 94), ello quiere decir que la representación de la masculinidad hegemónica en estas películas de una forma tan rígida, no solo obedece a la realidad social, sino que también sirve como mecanismo narrativo e histórico que fija la identidad sufragista en torno a la resistencia y a la sororidad.

Con esto debe tenerse en cuenta los comentarios al respecto de las alteridades sexuales como exterioridad constitutiva de Judith Butler (2002: 20): “[1]a formación de un sujeto exige una identificación con el fantasma normativo del "sexo" y esta identificación se da a través de un repudio que produce un campo de abyección, un repudio sin el cual el sujeto no puede emerger". En este sentido el fantasma normativo de la masculinidad hegemónica y con ello de la sociedad masculinista fuerza a la exclusión de la sufragista, abonando el espacio fronterizo entre la marginalización y la norma que da lugar a dispositivos de violencia que se despliegan ininterrumpida y constantemente debido a que "esa abyección rechazada amenazará con exponer las presunciones propias del sujeto sexuado" (Butler, 2002: 20). Su identidad colectiva como mujeres y como ciudadanas aglutinaba los ejes argumentales sobre los que el liberalismo había construido la soberanía de los varones: el sexo masculino y el ciudadano como lo universalmente humano.

Si las representaciones culturales, tal y como se ha afirmado, hicieron de la propaganda antisufragista, en el auge de los medios de comunicación de masas, un claro mecanismo de subalternidad, lo cierto es que la identidad sufragista debe ser entendida como una forma de resistencia (Nash, 2006: 40), un espacio de articulación de alteridades así como de rei (vindicación) del espacio público y reconsideración de las rígidas divisiones victorianas que lo separaban de lo doméstico. Pero estas militantes no solo demostraron que la respuesta violenta, no contra vidas humanas, cargada de consistencia política fue necesaria como respuesta reactiva, sino que además hicieron uso de nuevas formas de activismo, así como de los medios propagandísticos a los que tuvieron acceso. El sufragismo se sirvió del capitalismo para extender y promocionar su ideología feminista y así conseguir sus objetivos. El "espacio de las idénticas" (Amorós, 2005), de la mujer en singular como una deidad doméstica se rompe cuando la rebeldía de mujeres en plural, unidas por una misma causa se enfrenta al statu quo en mayor o menor grado.

El cine recrea la Historia haciendo política porque la visibilización, la selección del tema, imágenes, los procedimientos técnicos, todo el engranaje fílmico, confluyen para crear una 
ilusión que no por ello deja de tener capacidad de modificación de la vida "real". En este sentido se ha decidido finalizar este texto con un párrafo extraído del Manifiesto de Femen (2015: 37), un movimiento heredero de las prácticas políticas espectaculares así como de la ocupación del espacio público de forma reivindicativa que bebe del feminismo más activo e incluso sufre las mismas críticas que sufrieron las sufragistas y que refleja como la desigualdad es un fracaso de todos y de todas, nuestro mayor fracaso:

"El constante resurgir de actos extremistas y violentos, cometidos contra las mujeres, se impone como síntoma del fracaso del modelo de sociedad que nuestras autoproclamadas democracias nos proponen. Tomar conciencia, no solo como mujer, sino como ser humano, de la crueldad que un sistema semejante puede engendrar, nos conduce a la constatación de un estrepitoso fracaso".

\section{BIBLIOGRAFÍA}

- Amorós, Celia (1998): "Política del reconocimiento y colectivos bi-valentes". En: LOGOS. Anales del Seminario de Metafísica. 32(1), pp.39-56.

. (2005): La gran diferencia y sus pequeñas consecuencias...para las luchas de las mujeres. Madrid: Cátedra.

- Anderson, Bonnie S. y Zinsser, Judith P. (1991): Historia de las Mujeres: una Historia propia. Barcelona: Editorial Crítica.

- Bondi, Liz (2003): "Empathy and Identification: Conceptual Resources for Feminist Fieldwork". En: ACME: An International E-journal for Critical Geographies, 2(1), pp. 64-76.

- Bourdieu, Pierre (2007): El sentido práctico. Buenos Aires: Siglo XXI Editores.

- Butler, Judith (2002): Cuerpos que importan: sobre los límites materiales y discursivos del "sexo". Barcelona: Paidós.

- Connell, Raewyn W. (2015): Masculinities. Reino Unido: Polity press.

- De Lauretis, Teresa (1987): Tecnologies of Gender. Essays on Theory Film, and Fiction. Indiana: Indiana University Press.

- Della Porta, Donatella y Diani, Mario (2006): Social Movements. An Introduction. EEUU: Blackwell.

- Duby, Georges y Perrot, Michelle (2003): Historia de las Mujeres. Volúmen 5: El siglo XX. Madrid: Taurus.

- Expósito, Francisca; Moya, Miguel C.; Glick, Peter (1998). "Sexismo ambivalente: medición y correlatos”. En Revista de Psicología Social, (13)2, 159-169.

- FEMEN (2015): Manifiesto Femen. Asturias: Hoja de Lata.

- Friedan, Betty (1963): The feminist mystique. London: Pengiun. 
- Gilmore, David D. (1990): Manhood in the Making: Cultural Concepts of Masculinity. EEUU: Yale University Press.

- González Hernández, María Jesús (2009): “Las sufragistas británicas y la conquista del espacio público; integración, recreación y subversión”. En: Arenal, 16(1), pp. 53-84.

- Halberstam, Judith (2008): Masculinidad femenina. Madrid: EGALES.

- Kimmel, Michael (1987): Changing men: New directions in research on men and masculinity, Newbury Park CA: Sage.

- Kuhn, Annette (1991): Cine de mujeres: feminismo y cine. Madrid: Cátedra.

- Nash, Mary (2006): “Identidades de género, mecanismos de subalternidad y procesos de emancipación femenina. En: CIDOB d'afers internacionals, pp. 39-57.

- Schippers, Mimi (2007): "Recovering the femenine other: masculinity, femininity and gender hegemony. En: Theory and society, vol. 36, $\mathrm{n}^{\circ} .1, \mathrm{pp} .85-102$.

- Sorlin, Pierre (2005): "El cine, reto para el historiador". En: ISTOR (Revista de Historia Internacional), 5(20), pp. 11-35.

- Valcárcel, Amelia (1994): Sexo y filosofia. Sobre “mujer” y “poder”. Barcelona: Anthropos. (1997): La política de las mujeres. Madrid: Cátedra. 
